Revista de la red interuniversitaria de estudios sobre las literaturas rioplatenses contemporáneas en Francia

\title{
De lo multicultural a lo interdisciplinario o cómo opera la ciencia ficción de Marcelo Cohen
}

Du multiculturel à l'interdisciplinaire ou comment fonctionne la science-fiction de Marcelo Cohen

From multicultural to interdisciplinary or how Marcelo Cohen's science fiction operates

\section{Ricardo Torre}

\section{(2) OpenEdition}

\section{Journals}

Electronic version

URL: http://journals.openedition.org/lirico/8803

DOI: $10.4000 /$ lirico.8803

ISSN: 2262-8339

Publisher

Réseau interuniversitaire d'étude des littératures contemporaines du Río de la Plata

\section{Electronic reference}

Ricardo Torre, «De lo multicultural a lo interdisciplinario o cómo opera la ciencia ficción de Marcelo Cohen », Cuadernos LIRICO [En línea], 20 | 2019, Publicado el 10 julio 2019, consultado el 02 junio 2020. URL : http://journals.openedition.org/lirico/8803 ; DOI : https://doi.org/10.4000/lirico.8803

This text was automatically generated on 2 June 2020

\section{(c) (†) $\odot$}

Cuadernos LIRICO está distribuido bajo una Licencia Creative Commons Atribución-NoComercialSinDerivar 4.0 Internacional. 


\section{De lo multicultural a lo interdisciplinario o cómo opera la ciencia ficción de Marcelo Cohen}

Du multiculturel à l'interdisciplinaire ou comment fonctionne la science-fiction de Marcelo Cohen

From multicultural to interdisciplinary or how Marcelo Cohen's science fiction operates

Ricardo Torre

\section{Introducción}

Si en la década de los ochenta y de los noventa, la obra narrativa de Marcelo Cohen tiene la particularidad de presentar escenarios multiculturales, de mezcla de culturas (Insomnio, 1985; El oído absoluto, 1989; El testamento de O'Jaral, 1995, por solo citar tres de sus novelas más conocidas), a partir del siglo XXI el corpus constituido por su producción literaria se tiñe de matices que podrían calificarse de "interdisciplinarios". Desde la publicación del volumen Los acuáticos (2001) hasta su último libro de relatos La calle de los cines (2018), Cohen ha pasado casi veinte años cartografiando el Delta Panorámico, el universo infinito de islas de río que es sede y campo de experiencias literarias de sus últimas ficciones. En clara ruptura con el realismo mágico latinoamericano o con el fantástico practicado por Cortázar o Borges, la estética coheniana desborda los cánones y tradiciones rioplatenses para conformar una "sociología fantástica" (expresión de Cohen) cuya aplicación inmediata se efectúa en una ciencia ficción de claros antecedentes en la New Wave de los años sesenta. Los mapas de la tradición literaria quedan, en Cohen, reconfigurados desde el momento en que el escritor argentino reivindica en su obra el peso de autores anglosajones de la talla de William S. Burroughs, Ray Bradbury, James G. Ballard o Christopher Priest. No es por nada que cuando se le pregunta a Cohen de dónde sacó la idea del Delta 
Panorámico, indica que su inspiración directa se encuentra en el Archipiélago de Sueño de La afirmación de Christopher Priest (novela publicada en inglés en 1981, The Affirmation). Si la interdisciplinariedad se entiende normalmente por la acción del estudio cruzado entre disciplinas de un mismo objeto (Lenoir 2013), podemos decir que la literatura de Marcelo Cohen es, en particular en el siglo XXI, interdisciplinaria en sentido amplio porque recupera y explota inquietudes propias tanto de varias ciencias sociales y humanas como de disciplinas artísticas. Si en Los acuáticos se cruzan las ciencias y las artes (la demografía y la acrobacia; las artes plásticas y la economía), en las grandes novelas Donde yo no estaba (2006) y Casa de Ottro (2009) las preocupaciones política, sociológica y psicológica están íntimamente ligadas al acto literario, al acto de escritura (la primera se presenta como el "diario" del protagonista y la segunda, como un conjunto de "papeles" y "fichas" redactadas por una socióloga, ex jefa de campaña de un gobernante fallecido).

2 En el presente trabajo nos detendremos primero en los escenarios multiculturales de las tres distopías de Cohen citadas previamente para reflexionar en su potencial creativo. En una segunda escala, exploraremos cómo la obra reciente de Marcelo Cohen opera cruces y síntesis entre disciplinas, permitiendo así una renovación en la literatura rioplatense contemporánea.

\section{Escenarios multiculturales en obras de Cohen del s. $\mathrm{XX}$}

3 Hemos señalado anteriormente que la producción literaria de Marcelo Cohen correspondiente al siglo pasado juega con la noción de lo múltiple y lo heterogéneo, y ésta se puede aplicar a las "culturas" en sentido amplio. Veamos cómo se manifiestan estos elementos en tres novelas ${ }^{1}$ del autor argentino.

4 En cuanto a la sociedad en la obra de Cohen, o más precisamente a sus sociedades ficticias, es menester comprobar que la heterogeneidad es un rasgo fundacional de lo social: la heterogeneidad de las sociedades presentes así como la heterogeneidad dentro de cada sociedad ficticia. Dos caracteres relacionados paradójicamente con estos dos signos distintivos son el de la mezcla y el de la fragmentación.

Del mismo modo como la sociedad argentina fue constituyéndose con mezclas, fruto de la inmigración, las sociedades de las obras de Cohen están construidas a base de mixturas, de acumulaciones, de aglomerados étnicos, culturales y socioeconómicos.

En el caso de la última novela citada, El testamento de O'Jaral, podemos decir que lo heterogéneo rima con lo fragmentado. La estructura social de Talecuona, la ciudad de la novela, es complejísima, y excede los límites de este trabajo el descomponerla en detalle. La fragmentación social es fruto de diferentes ideologías políticas que atraviesan el relato y de diferencias económicas que crean una brecha entre ricos y pobres, con distintas subcategorías (entre estos últimos, por ejemplo: los indefinidos sociales, los pobres propiamente dichos, los "borradores" humanos, etc.). Lo múltiple desde el punto de vista cultural se observa en una primera división: alta cultura / baja cultura. Y al final de la novela, las diferencias se estructuran en base a la dicotomía local / exterior. A distintos puntos de la ciudad llegan grupos de jóvenes caracterizados como "forasteros", "extraños", que tendrán una función de "normalizadores" (en el sentido de generadores de conflicto, que vendría a ser la situación "normal" buscada 
por el Gobierno) y que se convertirán, a nivel de la pensión-fonda La Garnacha en donde se aloja el protagonista, en "ocupantes" (Cohen 1995: 307-311, 314, 315, 320-324). Se nota claramente que para los "parroquianos" o los "inquilinos" de la pensión aquellos tienen una "cultura" muy diferente, en sus gestos, formas de hablar y comportamiento. Se indica al pasar los orígenes diversos de los jóvenes: "Son amerindios, germanos, mulatos o indioarios" (308), con lo que se refuerza la sensación de heterogeneidad al tiempo que se insiste en la oposición fragmentada con los "locales" de Talecuona.

7 Podemos ahora concentrarnos en dos novelas previas de Cohen, de los años ochenta. En Insomnio, la acción ocurre en una ciudad inventada de la Patagonia argentina llamada Bardas de Krámer. El mestizaje multicultural del escenario literario queda justificado por la historia misma de la ciudad: fundada a tres kilómetros del Atlántico por el capitán Bienvenido Krámer sobre un yacimiento de petróleo, la urbe crece de manera caótica. En una década, un millón y medio de habitantes venidos de todo el planeta llegan para instalarse en ella. La ciudad obtiene un estatuto de autonomía relativa respecto al Estado argentino en contrapartida de un impuesto anual para la comercialización del petróleo. Veinte años después del descubrimiento petrolífero, el yacimiento se seca y se produce la "barbarie": durante dos años, los inmigrantes quieren dejar Krámer y hordas de desempleados procedentes de la misma devastan las ciudades latinoamericanas en donde establecen residencia. Los ejércitos de la Liga Interamericana (denominados "Fuerza Interamericana" en la novela) deciden firmar un pacto de asistencia militar con la ciudad a los fines de restringir la salida de los habitantes a diez personas por día, designadas por sorteo (1994: 38-40).

Lo que nos interesa destacar aquí es que esta situación global de la acción llega como una recuperación analéptica después de que el lector, en el curso de las primeras páginas, se encuentra sucesivamente con el protagonista de origen judío (Ezequiel), un grupo de sudafricanos, otro de soldados estadounidenses, un personaje (Tadeo Farkas) del que se dirá que es húngaro, pero también polaco (1994: 9, 20), un portero camboyano, otros asiáticos, una inglesa... Con la historia retrospectiva de la ciudad, el narrador justifica la mezcla de nacionalidades que está lejos de ser homogénea y cuya sedimentación progresiva se resume en frases como la siguiente: "un aeródromo [...] y un ferrocarril [...] empezaron a arrojar [...] enjambres de inmigrantes de Buenos Aires, de Lima, de toda república africana donde los blancos ya no pudieran prosperar y de náufragos de los mares asiáticos" (39).

9 En su estudio precursor de la novela, Adriana Bergero relaciona estas oleadas de orígenes diversos y distantes con "el internacionalismo de las fuerzas de trabajo" que se produjo en Patagonia entre 1891 y 1914 a través de un fuerte impacto migratorio europeo a partir de "la crisis europea de acumulación del capital" (2002: 37). La investigadora destaca igualmente la "comunidad trans-étnica" de Bardas de Krámer, formada por "patagones, españoles, húngaros, mapuches, salteños, camboyanos, araucanos y afroamericanos" cuya "identidad colectiva [será] lograda por medio de lateralidad, vale decir, de la visualización de condiciones comunes al grupo arrojado a la diáspora por políticas económicas globales" (47, cursivas de la autora). Puede concluirse así que la sociedad de Bardas de Krámer no puede ser organizada en grupos definidos y homogéneos. Se trata más bien de un conglomerado disgregado de individuos de horizontes y orígenes diferentes. 
10 El caso de Lorelei en El oído absoluto es similar: no podemos hablar de sociedad estable y homogénea, este centro recreativo "internacional" acoge toda suerte de visitantes de todos los países, como se puede observar en cualquier descripción variopinta de sus turistas en la novela. Cabe destacar que los residentes de Lorelei también proceden de distintas naciones: hay españoles, argentinos, irlandeses... Personas y objetos venidos de todos los horizontes generan una sensación de caos, de fárrago, de conjunto heteróclito. Una larga tradición interpretativa, que comienza con Beatriz Sarlo, insiste en vincular todo lo que pasa en Lorelei y todo lo que es Lorelei con el período neoliberal argentino del gobierno de Carlos Menem en la década de 1989-1999 (Sarlo 2007, Bergero 2013). Pero, dado que la publicación de la novela antecedió al gobierno de Menem, preferimos adherir a la interpretación de Fernando Reati, que indica que Cohen, con su novela, escribe una sátira de la noción posmoderna que considera a la cultura como la hibridez de todo: de las influencias mezcladas, de las estéticas heterogéneas, etc. Entendida de esta manera, la posmodernidad no sería "un ensanchamiento de las opciones culturales", sino una acumulación desordenada tanto de chucherías, bagatelas como de ideologías (155).

11 Dos ejemplos bastan para ilustrar lo que acabamos de exponer. Uno concierne a productos comerciales. En Lorelei, se encuentran “jaurías de vendedores de máscaras camerunesas, amuletos haitianos, paraguas de Hong Kong, patos parlantes de Hong Kong, sombreros de paja, polaroids, garrapiñada, cebiche, piñas y aguacates y papayas, pelotas, baleros, minicadenas portátiles, cazalla, guitarras, berimbaus ${ }^{2 "}$ " (Cohen 1997: 80). Este conjunto hace eco a uno del mismo calibre que se halla en Insomnio. El protagonista llamado Ezequiel observa lo exhibido "en la feria de los pacientes", en donde se venden "patos mecánicos, helicópteros de control remoto, ajedreces de ónix, choclos asados, tortas fritas, pañuelos de Túnez y de Marruecos, medias de Hong Kong, calzoncillos de la India, camisas italianas" $(10,11)$ y un largo etcétera ${ }^{3}$.

12 El segundo ejemplo se relaciona con productos, esta vez, culturales. En el centro neurálgico de Lorelei, el Recinto Latino, los visitantes, además de poder ir al cine, al circo, a los casinos, bares o restaurantes, tienen una amplia oferta de espectáculos a los que asistir. Entre estos se encuentran "una versión de Macbeth adaptada al quechua por el Teatro Estable de Puno; [...] un concierto de bebop y otro de polos margariteños, una función de danzas balinesas [...]" (1997: 21) en una larga lista, ampliamente comentada por los investigadores, de casi veinte líneas.

13 Ya sea que consideremos estos elementos desde el punto de vista mercantil o bien cultural, se trata de una verdadera acumulación que está inscrita explícitamente en la novela por la voz de un visitante, Lotario, el padre de la novia del narrador: “-Caracho... Qué amontonamiento [...] / [de nuevo él] -[...] Llenar todo, ocupar el espacio [...]”. Acumulación de la que se hace eco en la cita siguiente igualmente Lino, el protagonistanarrador-escritor, quien, hablando del Recinto Latino, pero por extensión de Lorelei, indica: "me pregunto si esta novela saturada de palabras no será apenas un síntoma tardío". En la cúspide de la ideología de un capitalismo posmoderno, híbrido y kitsch, Lino sintetiza a la perfección la esencia de Lorelei: "la más perversa ilusión de la mente liberal" (82).

14 La acumulación de objetos comerciales y culturales crea un efecto de serie de "enumeración caótica", central en la poesía del s. XX, estudiada minuciosamente por Leo Spitzer (1945) y practicada, entre otros, por Borges (Giraud 2016). Muchas son las aristas interpretativas que pueden desprenderse de este recurso. En primer lugar, 
Cohen (con novelas como El país de la dama eléctrica, Insomnio o El oído absoluto) crea un escenario para crear una lengua. En este sentido, la mezcla es fundamental. La invención de escenarios conlleva la creación de una lengua reconocible, y que se ilustra con las acumulaciones seriales anteriores. En segundo lugar, estas enumeraciones son "omniabarcativas" y provocan un fenómeno de descategorización, que se relaciona con una voluntad que podría calificarse de "anti-local”, "anti-nacionalista". Y por último, la enumeración caótica funciona dentro de la ciencia ficción coheniana como ejercicio poético que hace estallar la certeza, que pone en duda la verdad, que provoca extrañeza en el lector y que vehicula un fenómeno de inestabilidad con y en el discurso ${ }^{4}$.

Cabe destacar que este "rizoma" (más que línea) interpretativo está en total coherencia con las declaraciones y reflexiones del mismo Cohen, que parten de dos direcciones: la experiencia del exilio (voluntario en Barcelona) y el trabajo de la lengua en literatura. Desde este último aspecto, Cohen ha comentado que su objetivo era efectuar un trabajo artesanal sobre la frase, pero a partir del idiolecto rioplatense, cuyas raíces "fueron retrabajadas y puestas al servicio de la narrativa por una serie de escritores que van desde Borges hasta Onetti [...], pasando por algunos hitos muy peculiares como Di Benedetto, Felisberto Hernández o Marechal, entre otros." De estas referencias literarias mayores, nuestro autor vincula lenguaje e invención de espacios mixtos: "Esta elección de lenguaje tiene que ver con que yo necesitaba que ese espacio sincrético funcionara a partir de una maquinaria verbal que me ligara a esta cultura." (Cohen apud Saavedra 1993: 87, 88).

En dos entrevistas (Saavedra 1993, Speranza 1995), Cohen cita su experiencia vital de exiliado en conexión con la lectura de J. G. Ballard como fuente de la creación de sus escenarios o espacios "sincréticos" o "sintéticos". Las intervenciones siguientes arrojan una luz aclaradora con respecto a las "enumeraciones caóticas" de Insomnio y de El oído absoluto:

[...] quería contar historias que tuvieran que ver con mis fuentes imaginativas privadas [...] y con un mundo de referencias que, no por ser disperso, yo veía dislocado. No estoy hablando del exilio como una situación histórica concreta, sino de un mundo en donde convivían el ordenador, los pases de fronteras, la inestabilidad y los tamales de humita. Esta situación no es solo el resultado de una escisión entre culturas como la que sufren los exiliados; también se verifica en lugares y personas del mundo desarrollado, donde la alpargata sigue coexistiendo con el jumbo (Saavedra 1993: 85).

[Las reflexiones sobre la literatura realista, fantástica y de ciencia ficción] me sirvieron para solucionar el problema del exilio, para crear espacios sintéticos donde pudiera hablar el sedimento de mi experiencia, donde las calles de adoquines entre las cuales crecen los yuyos y el borracho de un parque, dormido, abrazado a una muleta, pudiera convivir con otras cosas que yo había visto en el llamado Primer Mundo y que no tienen nada que ver con eso: el universo de la autopista, la perversión tecnológica. Ballard lee el paisaje posindustrial como una patología mental. Dice que ese paisaje es nuestra mente.

[...]

Esos lugares inventados [Bardas de Krámer y Lorelei] también tienen que ver con una reflexión que se hace en los viajes, aquí o en cualquier otro lugar sobre aquello que la corrosión, las acumulaciones, la vecindad de lo heteróclito, expresan sobre la condición de la mente contemporánea (Speranza 1995: 77, 78; cursivas en el original).

17 Así, "la vecindad de lo heteróclito" confirma la heterogeneidad multicultural presente en las novelas de Cohen del siglo pasado, heterogeneidad que podría "pensarse como 
una versión exasperada de la tradición de mezcla cultural argentina" (Speranza 1995: 78). Si hemos comprobado que en el siglo XX Cohen propone espacios virtuales en los que se da una coexistencia de objetos, valores y culturas, veremos que en el siglo XXI el autor argentino practica otro tipo de combinatoria.

\section{Giro interdisciplinario en el s. XXI} el que inaugura un nuevo ciclo literario (Torre 2018) que tiene como escenario común el universo fluvial del Delta Panorámico. La hipótesis que intentamos probar en este estudio es que del marco multicultural que caracterizó a la mayor parte de la narrativa coheniana (si no a toda) se pasa, con el Delta Panorámico, a una producción en donde destaca el cruce interdisciplinario. A continuación, con ayuda de varios fragmentos y ejemplos, proponemos rastrear algunas disciplinas en juego y explorar la naturaleza de las interrelaciones elegidas por el escritor.

Podemos comenzar por el origen de todo: el íncipit de "El fin de la Palabrística", que es el íncipit de Los acuáticos y que, en consecuencia, es el íncipit de todo el Delta Panorámico:

En una situación de grandes apreturas generales surgió un hombre que miraba hacia arriba. Sí. Bueno, sí. Es un planteo inicial firme y acertado pero muy insuficiente. Hacen falta algunas consideraciones. Apreturas, por ejemplo, significa no que no hubiese dinero sino que costaba mucho moverse con soltura; que, aunque la comodidad de las casas permitiera soslayar por las noches cuánto se chocaba durante el día en la calle, estaba el límite cortante donde los últimos edificios daban la espalda al campo arruinado por encima de la Perimetral (Cohen 2014: 309).

Este principio un tanto enigmático juega con ambigüedades que se van resolviendo progresivamente. La primera -resuelta inmediatamente- concierne al "planteo inicial" con la polisemia del término "apreturas". Se juega con la acepción que debe descartarse (la económica) y con la que debe guardar en mente el lector a fin de comprender la historia. Esta última conjuga dos dimensiones, una física y una disciplinar. La dimensión física es evidentemente el espacio ("costaba mucho moverse con soltura") y la disciplinar será revelada posteriormente: la demografía. "Cuánto se chocaba durante el día en la calle" actúa como un disparador de sentido que se colmará cuando el lector descubra el verdadero problema de Ciudad Ajania: la falta de lugar originada por la sobrepoblación urbana.

21 Comentaremos también brevemente -por haberlo expuesto en otro lugar (2018: § 34, 35)- que este íncipit rezuma otra pista disciplinar. La frase "estaba el límite cortante donde los últimos edificios daban la espalda al campo arruinado por encima de la Perimetral" será desarrollada a lo largo de la historia, en una clara oposición centroperiferia, configurada de la manera siguiente: aproximadamente en el centro de la isla del relato fue fundada Ciudad Ajania, separada del resto de la isla por una muralla llamada Ronda Perimetral. La ciudad se caracteriza por sus rascacielos, su tecnología; la periferia (el "campo arruinado", que incluye las costas) está marcada por la violencia y el atraso. Incluso dentro de la Ciudad, quienes viven cerca de la Perimetral, o sea alejados del centro, también son marginados, por no tener los mismos valores que los ajanios del centro (por ejemplo, el que familias numerosas vivan en casas de planta en 
habitaciones diminutas). La disciplina que puede convocarse en este caso es claramente la geografía social.

En el segundo cuento largo de Los acuáticos titulado "Un montón de adjetivos", el lector no debería sorprenderse con la oposición socioeconómica y cultural (nuevamente Cohen juega con la geografía social) que se describe entre el "adentro" y el "afuera" del punto de vista del personaje central desde el cual se focaliza la acción. El adentro representa el ex salón de juntas del Hotel Isla Brunica en donde se hace la inauguración de una exposición e instalación artísticas. El afuera son las riberas de la isla. El primero es un mundo de frivolidad, cócteles, riqueza, opulencia y apariencias, mientras que el segundo -periférico a más no poder- muestra la precariedad total de los cangrejeros de la isla, que viven en "casuchas" (354) miserables (Torre 2018: §36, 37). En este relato Cohen también utiliza códigos de la sociología, ya que, si bien las mujeres tienen nombres propios (Leandra, Melaní...), los personajes masculinos solo son designados con la abreviatura de "sujeto" ("Suj.") seguido de un número, como si se tratara de algún tipo de estudio:

El hombre era, así lo llamaremos, Suj.1, un publicitario de temperamento flemático.

[...] En cuanto vio a Suj.1 perderse en el gentío se dejó sorber por un grupito cuyo animador, cierto Suj.2, elogió la truculencia de la escena del living y las veladuras de algunos óleos. [...]

De ese conjunto destacan dos hombres: Suj.3 y Suj.4. Puede que los dos sean esnobs. Puede que sean infantiles, lunáticos (Cohen 2014: 342, 343, 352).

Las disciplinas citadas (disciplinas "humanas", ciencias humanas y sociales) no son las únicas que intervienen en la configuración de la historia. Podemos volver a estos dos relatos para captar las relaciones que se dan entre ellas.

Desde el punto de vista literario, "El fin de la Palabrística" se presenta como una parodia de literatura policial, ya que se autodefine como el informe de un sargento sobre las circunstancias de una muerte sin cadáver. En este informe se tejen las relaciones complejas entre las disciplinas. A partir del extracto siguiente, podremos indicar de qué disciplinas y relaciones se trata:

En una situación de grandes apreturas generales surgió un hombre que miraba hacia arriba. Su imaginación nostálgica concibió el deporte de alzar andamios humanos para escribir en el cielo las palabras de la ambición. El impulso grupal agigantó las construcciones. Les dio belleza artística. Ciudad Ajania supo que podía hacer concretos espacios nuevos llevando el verbo cada vez más alto (336).

El sargento Doriac debe escribir su informe sobre la supuesta muerte de Viol Minago, el también supuesto fundador de una disciplina artística y deportiva particular que combina la acrobacia y el lenguaje. A partir de un problema demográfico (las "grandes apreturas generales" del íncipit retomado aquí que simbolizan la sobrepoblación urbana), un héroe casi mítico crea la "Palabrística", el arte y deporte de construir palabras y frases con cuerpos humanos ("andamios humanos para escribir en el cielo las palabras de la ambición"). Lo que podemos destacar aquí es la interrelación generada entre las disciplinas: disciplinas conjuntas (acrobacia + lenguaje) que vienen a proponer una solución a un problema generado por un fenómeno estudiado por otras disciplinas (demografía).

En el caso de la comedia de enredos, o comedia romántica, que constituye "Un montón de adjetivos", las artes y las ciencias humanas también forman la base de la historia:

De su estancia experimental en las chozas de la ribera Leandra guarda, además de

cuadros documentales intensos, algunas amistades cautelosas pero duraderas. No se 
siente turista cuando las visita, ni perdonavidas. Y esta vez va a las chozas, como todas las pocas veces que va, solamente de visita, a buscar imágenes de verdad, sabiéndose tan inepta para la pintura realista como para hacer en la tela tajos que signifiquen algo (354).

Una de las protagonistas de la historia es la artista plástica Leandra Chenán. Una parte importante de la inauguración de la que hablábamos previamente está constituida por una exposición pictórica de veintiséis cuadros. En este caso -como bien puede percibirse en el pasaje anterior-, la pintura ("cuadros documentales intensos") se combina con la exploración etnográfica de las poblaciones desfavorecidas socioeconómicamente hablando ("estancia experimental en las chozas de la ribera"). Se puede indicar de este modo que, como en el caso anterior, la asociación de campos disciplinarios y artísticos permite el desarrollo del relato.

Antes de pasar a efectuar observaciones sobre lo interdisciplinario en obras posteriores de Cohen, podemos esquematizar lo dicho en el cuadro siguiente para resaltar la presencia de las disciplinas en estos dos cuentos largos de Los acuáticos:

\begin{tabular}{|c|c|c|}
\hline & Disciplina humana & Disciplina artística \\
\hline \multirow[t]{2}{*}{ "El fin de la Palabrística" } & $\begin{array}{l}\text { - demografía } \\
\text { - geografía social }\end{array}$ & - acrobacia + lenguaje \\
\hline & \multicolumn{2}{|c|}{ parodia de literatura policial } \\
\hline \multirow[t]{2}{*}{ "Un montón de adjetivos" } & $\begin{array}{l}\text { - sociología } \\
\text { - geografía social }\end{array}$ & - artes plásticas + etnografía \\
\hline & \multicolumn{2}{|c|}{ comedia de enredos, comedia romántica } \\
\hline
\end{tabular}

En obras posteriores, que no entren en el ciclo del Delta (como Impureza, publicada como cuento en un volumen colectivo en 2004 y como novela corta separada en 2007) o que sí lo conformen plenamente (Donde yo no estaba, 2006; Casa de Ottro, 2009; Balada, 2011...), Cohen prosigue, desde la óptica especial de su "sociología fantástica", la exploración de campos disciplinarios ligados a la política, la sociología, las artes o la psicología. Como prueba de lo dicho, daremos algunos ejemplos y nos detendremos luego en un motivo particular. Entre los ejemplos, hemos indicado en la introducción que nuestro autor plasma en sus grandes novelas inquietudes sociopolíticas estrechamente relacionadas con el acto de escritura. Donde yo no estaba no es "más que" el diario de un comerciante acomodado que se posiciona en contra de las autoridades de su isla. Abundan, entonces, las reflexiones y comentarios sobre la intervención de la política (de la "Democracia Gentil", como sistema de gobierno futurista) en la vida social e individual de los personajes. Casa de Ottro combina sociología y política desde su postulado de base: la novela se presenta como una sucesión de "papeles" y "fichas" escritas por una socióloga que fue jefa de campaña y asesora de un ex gobernante local. Un último ejemplo lo puede constituir la simbiosis fantástica operada entre el cine y la literatura en el último compendio coheniano: $L a$ calle de los cines. Inscribiéndose propiamente del lado de la ficción, el autor presta su nombre a un nativo de Isla Onzena, y así un habitante del Delta Panorámico llamado "Marcelo Cohen" en el mes de noviembre del estarco III del ciclo de las Algas (2018:17) compartirá con los lectores un conjunto de dieciocho "filmes" que le han gustado. Y no es una sorpresa que en estos se 
hallen preocupaciones sociopolíticas: "Un filme sobre la violencia social" es el subtítulo del quinto de ellos.

El motivo al que aludimos arriba ilustra las relaciones interdisciplinarias entre la psicología y la sociología. Desde fines de los años noventa, y en muchos relatos y novelas, se presenta la imagen espacial externa de una cabina en donde ejerce un personaje a quien se llama el sociólogo o consejero social, o bien: (psico)terapeuta, psicólogo o asesor social / terapéutico. Las sesiones con este personaje tienen lugar en "cabinas": "cabina" de manera general, "cubículo" o "quiosco" en Impureza, "cabina" o "cubículo" en Balada. Se trata normalmente de un espacio de observación (en el cuento "Tristezas de una tarde de sábado" y en la novela Casa de Ottro) y de comunicación (en todas las historias) entre los pacientes (comúnmente pobres) y el sociólogo/terapeuta. Sobre todo es un lugar de escucha y de habla, de intercambio verbal, de discurso que crea la historia en alguna medida. Recogemos en el cuadro siguiente los términos utilizados según la ficción:

\begin{tabular}{|l|l|l|}
\hline lugar & profesional & relato / novela \\
\hline Cabina de Asistencia Anímica & sociólogo & “Tristezas de una tarde de sábado” \\
\hline cabina de asistencia psicológica & terapeuta & Donde yo no estaba \\
\hline quiosco (de tablas), cubículo & psicólogos & Impureza \\
\hline cabina & asesor social & Casa de Ottro \\
\hline cabina & asesor terapéutico & Balada \\
\hline
\end{tabular}

Es notable la sustitución entre los papeles de sociólogo y psicólogo. Como si el tratamiento de las situaciones particulares de los personajes no pudiera ser independiente de una interdisciplinariedad manifiesta entre los dos campos de las ciencias humanas que estos especialistas representan. No sería inútil preguntarse hasta qué punto el personaje que desempeña el papel de asesor estructura la vida social a través del prisma de su mirada y de sus reflexiones sobre las acciones y su contexto. Dicho de otro modo, hasta qué punto ese papel de emanación de la palabra permite construir el universo de ficción.

Como hemos podido comprobar con los elementos anteriores, Marcelo Cohen efectúa en su literatura un giro interdisciplinario en el nuevo milenio. Juega con los campos del saber, cruza disciplinas y genera ficciones ricas en interrelaciones entre artes y ciencias humanas o sociales.

\section{Palabras finales}

Este breve recorrido por algunos hitos de la obra de Marcelo Cohen nos ha llevado a corroborar que multicultural e interdisciplinario son dos categorías funcionales en la producción del autor argentino. Fijando como "divisoria de aguas" del análisis el comienzo del nuevo milenio -límite que se justifica, además internamente, por la inauguración del ciclo del Delta Panorámico con Los acuáticos-, pudimos observar 
fenómenos diferentes en la producción del escritor argentino. En obras del s. XX priman los escenarios de mezcla de culturas, espacios virtuales, sincréticos o sintéticos, que se forjaron a partir de la experiencia vital del exilio, de la percepción y reelaboración de un contexto heteróclito, y de la necesidad de crear una lengua propia en un mundo propio. A partir del s. XXI pudimos verificar que la narrativa de Cohen se nutre con y se caracteriza por una confluencia productiva de campos disciplinarios diferentes pero magistralmente conjugados. Agreguemos que, para justificar este entrecruzamiento de disciplinas en la obra de Cohen, tenemos que acudir a los fundamentos, a las raíces de la ciencia ficción coheniana. Estas se encuentran en tendencias de la New Wave, la Nueva Ola anglosajona.

Esta corriente literaria en la ciencia ficción de los años sesenta y setenta "buscó una renovación del género basada tanto en un mayor cuidado lingüístico-expresivo como en la experimentación literaria" (Moreno 2010: 462). Siguiendo postulados de Ballard, no es una ciencia ficción que pondrá en escena viajes espaciales, interestelares, descubrimiento de otros planetas y de extraterrestres. No se sondea el espacio exterior y el futuro lejano, sino que se exploran el futuro cercano y el espacio interior. Cohen fue moldeando su literatura con estos principios en mente a partir de los años ochenta, y es evidente que, al igual que los representantes más característicos de la Nueva Ola, incluyó en sus relatos y novelas problemáticas de órdenes social, político y económico, entre otros. Lo que hemos observado es que a partir del nuevo milenio y del nuevo ciclo del Delta, además de puntualizar que la acción no transcurre en un futuro próximo sino lejano, Cohen refuerza la presencia e interacción de disciplinas artísticas y de las ciencias humanas y sociales.

El género peculiar en que se mueve el escritor argentino él lo ha bautizado "sociología fantástica". Dejemos que él mismo lo defina:

[Revista Paco] -Al hablar de su literatura se suele decir que es anticipatoria y siempre se la encasilla dentro de la ciencia ficción. Usted, en cambio, a la hora de ponerle un nombre, habla de "Sociología fantástica", ¿cuáles son las diferencias entre la ciencia ficción tradicional y lo que usted hace?

[M.C.] -¡Quizás no haya muchas diferencias! Son artimañas que uno tiene para evitar la inclusión definitiva en un tipo de género. Es sociología fantástica porque lo que mueve mi imaginación es la búsqueda, la atención a ciertos elementos del funcionamiento social, en el cual podemos incluir la tecnología, los modos de comunicación, las costumbres, las modas y todo tipo de relaciones sociales, como las pueden definir distintos sociólogos. Lo que me interesa es estar atento a ese magma de la vida social, encontrar pequeños datos desatendidos que a mí me sobresaltan y trasladarlos a un momento en que pueden haber prosperado. De manera que la traspolación de detalles a su máxima potencia, en un vago futuro crea argumento. Eso sería la sociología fantástica. (Varela Pagliaro 2014).

Vemos, así, cómo lo social en sentido amplio (con todo el campo disciplinario que puede estudiarlo) se convierte en fuente de elaboración de ficciones. 0 , como nos lo sugirió Julio Premat y a quien agradecemos, la sociología fantástica coheniana puede ser entendida como maquinaria productiva, como sistema de producción, alegoría de concepción de la literatura. El cruce de disciplinas en el tratamiento de inquietudes de diversas índoles crea relato. La sociología fantástica de Cohen es origen y fin último de su literatura. 


\section{BIBLIOGRAPHY}

Bergero Adriana J. (2002), “Desindustrialización, espacio global y gestión colectiva en Insomnio, de Marcelo Cohen”, Hispamérica n 93, diciembre, p. 35-47.

--- (2013), “Front-stage/back-stage: segundas vidas en la dimensión social del espacio de la ciudad neoliberal”, Amerika. Mémoires, identités, territoires n 9, diciembre, Web. Consultado el 16/06/2019.

Cohen Marcelo (1994), Insomnio, Buenos Aires, Paradiso [1985].

--- (1995), El testamento de O’Jaral, Buenos Aires / Madrid, Alianza Editorial / Anaya \& Mario Muchnik.

--- (1997), El oído absoluto, Buenos Aires, Grupo Editorial Norma [1989].

--- (2001), Los acuáticos. Historias del Delta Panorámico, Buenos Aires, Grupo Editorial Norma.

--- (2006), Donde yo no estaba, Buenos Aires, Grupo Editorial Norma.

--- (2007), Impureza, Buenos Aires, Grupo Editorial Norma [2004 en volumen colectivo].

--- (2009), Casa de Ottro. Una historia del Delta Panorámico, Buenos Aires, Alfaguara.

--- (2011), Balada. Una historia del Delta Panorámico, Buenos Aires, Alfaguara.

--- (2014), Relatos reunidos, Buenos Aires, Alfaguara.

--- (2018), La calle de los cines, Madrid, Editorial Sigilo.

Giraud Paul-Henri, “"Pronto sabré quién soy". L’énumération chaotique" dans la poésie de Jorge Luis Borges", Nuria Rodríguez Lázaro (ed.), Rime et raison. Poésie et philosophie dans le domaine hispanique contemporain, Burdeos, Presses Universitaires de Bordeaux, 2016, p. 217-229.

Lenoir Yves, "Interdisciplinariedad en educación: una síntesis de sus especificidades y actualización", Interdisciplina I no 1, México D.F., Universidad Nacional Autónoma de México, septiembre-diciembre 2013, p. 51-86, Web. Consultado el 16/06/2019.

Moreno Fernando Ángel, Teoría de la literatura de ciencia ficción : poética y retórica de lo prospectivo, Vitoria, Portal Editions, 2010.

Reati Fernando O., Postales del porvenir: la literatura de anticipación en la Argentina neoliberal (1985-1999), Buenos Aires, Editorial Biblos, 2006.

Saavedra Guillermo, "Marcelo Cohen. Los espacios imaginarios del narrador", La curiosidad impertinente: entrevistas con narradores argentinos, Rosario, B. Viterbo, 1993, p. 79-93.

Sarlo Beatriz, Escritos sobre literatura argentina, Buenos Aires, Siglo Veintiuno Editores, 2007.

Speranza Graciela, "Marcelo Cohen”, Primera persona: conversaciones con quince narradores argentinos, Buenos Aires, Norma, 1995, p. 65-84.

Spitzer Leo, La enumeración caótica en la poesía moderna, Buenos Aires, Imprenta y Casa editora Coni, 1945. Traducción de Raimundo Lida.

Torre Ricardo, "El río y la ciudad en la obra de Marcelo Cohen", Cuadernos LIRICO no 18, octubre 2018, Web. Consultado el 16/06/2019.

Varela Pagliaro Nando, Entrevista "Marcelo Cohen: Un futurismo sudaca", Revista Paco, 7 de octubre 2014, Web. Consultado el 16/06/2019. 


\section{NOTES}

1. Para la caracterización de los centros urbanos de estas novelas, véase nuestro artículo, publicado en esta revista (2018: § 9-11).

2. No podemos omitir la mención de que "berimbau" es un término escrito directamente en portugués; este instrumento de música brasilero se dice "birimbao" en español. La mixtura se encuentra aquí también a nivel lingüístico. Reati (2006: 155) cita y comenta este pasaje.

3. Curioso es comprobar que Krämer (siendo "Krámer" la hispanización del apellido del fundador de la ciudad a la que prestó su nombre) es, por un lado, un regionalismo alemán que significa "tendero" (es decir, un término íntimamente ligado al comercio) y, por otro, una voz peyorativa que se traduce ora por "tacaño", ora por "mercachifle" (hemos consultado el Diccionario en línea Pons, sub voce "Krämer"). En una retahíla de improperios, en un discurso de pensamientos de Ezequiel que incluye un apóstrofe dirigido a los gobernantes, resuenan las constelaciones de sentido de la palabra alemana: "Y sin embargo, ¿quiero salir? ¿Quiero salir, mercachifles, cafishios del progreso económico, guanacos de la planificación social, fantoches, malparidos?" (fragmento en cursiva en el original; constituye el comienzo del pasaje escogido para la contratapa de la última edición de la novela) (Cohen 1994: 82).

4. Las interpretaciones y comentarios que se hallan en este párrafo (al igual que los entrecomillados) provienen de finas observaciones que de manera harto pertinente nos fueron propuestas por Edgardo Dobry, a quien agradecemos tales contribuciones a nuestro trabajo.

\section{ABSTRACTS}

If in the eighties and nineties, Marcelo Cohen's narrative work has the particularity of presenting multicultural scenarios, a mixture of cultures (Insomnio, 1985; El oído absoluto, 1989; El testamento de O'Jaral, 1995, just to cite three of his best-known novels), from the twenty-first century onwards the corpus constituted by his literary production is tinged with nuances that could be described as "interdisciplinary". We propose to explore this interdisciplinarity of the cohenian work, in the sense that it recovers and exploits the concerns of various social and human sciences as well as artistic disciplines.

Si en la década de los ochenta y de los noventa, la obra narrativa de Marcelo Cohen tiene la particularidad de presentar escenarios multiculturales, de mezcla de culturas (Insomnio, 1985; El oído absoluto, 1989; El testamento de O'Jaral, 1995, por solo citar tres de sus novelas más conocidas), a partir del siglo XXI el corpus constituido por su producción literaria se tiñe de matices que podrían calificarse de "interdisciplinarios". Proponemos explorar esta interdisciplinariedad de la obra coheniana, en el sentido de que ésta recupera y explota inquietudes propias tanto de varias ciencias sociales y humanas como de disciplinas artísticas.

Si au cours des années quatre-vingts et quatre-vingt-dix, l'œuvre de fiction narrative de Marcelo Cohen se caractérise par des espaces multiculturels, de mélange culturel (Insomnio, 1985 ; El oído absoluto, 1989 ; El testamento de O'Jaral, 1995, pour ne citer que trois parmi ses romans les plus connus), à partir $\mathrm{du} \mathrm{XXI}{ }^{\mathrm{e}}$ siècle sa production littéraire intègre des nuances que l'on pourrait qualifier d'interdisciplinaires". Nous nous proposons d'explorer cette interdisciplinarité de 
l'œuvre littéraire cohenienne, dans le sens que celle-ci récupère et exploite des inquiétudes propres aussi bien à plusieurs sciences sociales et humaines qu'à des disciplines artistiques.

\section{INDEX}

Mots-clés: Marcelo Cohen, littérature argentine du XXe et du XXIe siècle, science-fiction, multiculturel, interdisciplinarité

Keywords: Marcelo Cohen, Argentine Literature 20th-21st centuries, Science fiction, multicultural, interdisciplinarity

Palabras claves: Marcelo Cohen, literatura argentina de los siglos XX y XXI, ciencia ficción, multicultural, interdisciplinariedad

\section{AUTHOR}

\section{RICARDO TORRE}

Université Paris-Est Créteil

rstorre1@yahoo.fr 